\title{
Effectiveness of Urban Shelter-in-Place. III: Commercial Districts
}

Wanyu R. Chan ${ }^{\mathrm{a}, \mathrm{b}}$, William W Nazaroff ${ }^{\mathrm{c}}$, Phillip N. Price ${ }^{\mathrm{b}}$, Ashok J. Gadgil ${ }^{\mathrm{b}}$

${ }^{a}$ Environmental Sciences, Exponent, Inc., Bellevue, WA 98007, USA

${ }^{\mathrm{b}}$ Indoor Environment Department, Environmental Energy Technologies Division, Lawrence Berkeley National Laboratory, Mailstop 90R3058, Berkeley, CA 94720, USA

${ }^{c}$ Department of Civil and Environmental Engineering, University of California, Berkeley, CA 94720-1710, USA

\section{Abstract}

In the event of a toxic chemical release to the atmosphere, shelter-in-place (SIP) is an emergency response option available to protect public health. This paper is the last in a three-part series that examines the effectiveness of SIP at reducing adverse health effects in communities. We model a hypothetical chemical release in an urban area, and consider SIP effectiveness in protecting occupants of commercial buildings. Building air infiltration rates are predicted from empirical data using an existing model. We consider the distribution of building air infiltration rates both with mechanical ventilation systems turned off and with the systems operating. We also consider the effects of chemical sorption to indoor surfaces and nonlinear chemical dose-response relationships. We find that commercial buildings provide effective shelter when ventilation systems are off, but that any delay in turning off ventilation systems can greatly reduce SIP effectiveness. Using a two-zone model, we find that there can be substantial benefit by taking shelter in the inner parts of a building that do not experience direct air exchange with the outdoors. Air infiltration rates vary substantially among buildings and this variation is important in quantifying effectiveness for emergency response. Community-wide health metrics, introduced in the previous papers in this series, can be applied in pre-event planning and to guide real-time emergency response.

Keywords: infiltration, air-exchange rate, commercial buildings, toxic chemical, emergency response. 


\section{Introduction}

This paper is concerned with protection of the public from adverse health effects owing to the sudden outdoor release of an airborne toxic chemical in a city. Since many people in the downtown core of a city are in nonresidential buildings, the effectiveness of these buildings at protecting occupants from airborne chemical releases is important. Certain types of nonresidential buildings, such as shipping terminals and warehouses, might be associated with particularly high risks of experiencing a nearby toxic release because of the local handling and storage of hazardous materials. Politically, economically, or symbolically important buildings also might be targeted for malicious releases.

"Shelter-in-place" (SIP) refers to keeping building occupants indoors, closing doors and windows, and shutting off ventilation fans and dampers to minimize the entrainment of chemicals from outdoors into buildings. Where rapid evacuation is not possible, SIP might be the primary viable option to protect occupants from exposure to toxic chemicals released outdoors. General SIP guidelines exist for certain types of nonresidential buildings, e.g. schools (Sabiha et al., 2001) and workplaces (NICS, 2003). These tend to focus on the practicality of SIP, such as preparedness and advisable actions during an event. In the present analysis we quantify SIP effectiveness in a commercial building stock, considering variability in air infiltration among buildings and the importance of the operating state of the mechanical ventilation system. The influence of chemical sorption on indoor surfaces and the effect of SIP initiation and termination time delay are also addressed.

The present paper is the last in a three-part series on community-scale effectiveness of SIP and the factors that affect it. In the first paper (Chan et al., 2007a), we conducted a parametric investigation using an idealized representation of the system. In the second paper (Chan et al., 2007b), SIP effectiveness in a residential community was assessed using realistic transport and transformation models and input parameters. In those studies, we found that SIP effectiveness depends strongly on the degree of nonlinearity in the dose-response relationship. 
Time-scale parameters, such as the release duration and the building air-exchange rate, also significantly influence SIP effectiveness. For chemicals that sorb quickly to indoor surfaces, we found that timely termination of SIP is not very important for reducing casualties, and timely initiation of SIP is only moderately important. However, for nonsorbing chemicals with a linear dose-response relationship, it is essential for the community to implement SIP without time delay and to exit from shelter when it first becomes safe to do so.

In the present paper, a hypothetical toxic gas release is simulated in the downtown area of a city. The SIP effectiveness of commercial buildings is evaluated in terms of the casualty reduction factor (CRF) and the safety factor multiplier (SFM) (Chan et al., 2007a and 2007b). This assessment differs from our previous work on SIP in houses, because differences in building scale, in the leakiness of the building envelope (Sherman and Chan, 2006), and in ventilation system design and operation, can cause the SIP effectiveness of commercial buildings to differ from that of houses.

\section{Air Infiltration and Ventilation in Commercial Buildings}

\subsection{Air Leakage Measurements}

A pressurization test is a common technique for measuring air leakage of buildings (McWilliams, 2002). An external airflow $Q\left(\mathrm{~m}^{3} \mathrm{~s}^{-1}\right)$ is supplied to establish a pressure difference of $\triangle P(\mathrm{~Pa})$ in the building with respect to outdoors. Leaky buildings require a higher airflow than tight buildings to sustain a given pressure difference. The relationship between the measured parameters and the air-leakage characteristics of the building is typically represented as follows:

$$
Q=C \cdot A \cdot \Delta P^{n}
$$

where the air-leakage coefficient, $C\left(\mathrm{~m} \mathrm{~s}^{-1} \mathrm{~Pa}^{-n}\right)$, and the flow exponent, $n(-)$, are estimated by means of a curve fit to the pressurization test data. The parameter $A\left(\mathrm{~m}^{2}\right)$ is the surface area of the building envelope, often defined as the total surface area of the exterior vertical walls and 
roof of the building. Persily (1999) and Proskiw and Phillips (2001) have reviewed most of the whole-building pressurization test results of commercial buildings.

Price et al. (2006) analyzed leakage data from 267 commercial buildings in North America and Europe to look for systematic variation with construction materials, building type, height, and the country in which the building is located. Key findings are summarized here. The building leakage measurements are compiled from 15 studies (Fig. 1). The measured buildings are located in five countries, with the majority from the US (60\%), and others from Canada, UK, Sweden, and France. Buildings are classified into 12 different usage types and seven different construction types. Most of the buildings were built between 1960 and 2000. Many of the buildings $(60 \%)$ are small, with floor areas $<1000 \mathrm{~m}^{2}$. Approximately $75 \%$ of the buildings are single-story, but there are also 12 buildings that are 10-story or taller. The distribution of measured airflow, normalized by building envelope area and evaluated at $\Delta P=50 \mathrm{~Pa}\left(Q_{50} / A\right)$, is roughly lognormal with a geometric mean $(\mathrm{GM})$ of $4 \mathrm{~L} \mathrm{~s}^{-1} \mathrm{~m}^{-2}$ and a geometric standard deviation (GSD) of 2.3 .

Price et al. (2006) found small variation of the mean leakage parameter among construction types and large variability among buildings of a given type. For example, buildings of a nominally "leaky" construction type (e.g., wood-frame) have an average value of $Q_{50} / A$ that is about $5-15 \%$ higher than buildings of tighter construction types (e.g., concrete panel). Yet, among buildings of a given construction type, $Q_{50} / A$ can vary by an order of magnitude or more. Warehouses are associated with higher $Q_{50} / A$ values, as are buildings with a small footprint area and short height: these buildings can have $10-50 \%$ greater $Q_{50} / A$ than large, tall buildings. From the data, air-leakage statistical distributions were developed for buildings of different characteristics. Fig. 1 shows the predicted air leakage distribution $\left(Q_{50} / A\right)$ of small $\left(<1000 \mathrm{~m}^{2}\right.$ in footprint area and single-story) and large (>1000 $\mathrm{m}^{2}$ and $>6$-story) masonry office buildings in the US. The differences both in footprint area and in height contribute to the differences in leakage between the two groups of buildings. The distributions assume a GSD of 2.3, which is the observed variability among buildings. Note that the statistical distributions of air leakage 
described here represent rough estimates of the truth because of the small and nonrepresentative sample buildings tested.

\subsection{Air Infiltration Model}

We next consider air infiltration, by which we mean the entry of outdoor air when building ventilation systems are off. We apply a model developed by Shaw and Tamura (1977) to predict the airflow rate across the building envelope, without detailed consideration of the internal distribution of the infiltrating air. For this community-scale analysis, we chose this simple model over a multizonal model because the latter requires detailed site- and buildingspecific parameters (Price et al. 2004), which are impractical to collect on a large scale.

Modeling the air-infiltration rates for large buildings is more complicated than for small buildings. The driving forces are the same in both cases: wind, which exerts pressure on walls, and indoor-outdoor temperature difference, which induces buoyant flow (the "stack effect"). Larger buildings tend to have more internal partitions that can inhibit the development of stackeffect flows. On the other hand, structures like ventilation ducts, elevator shafts and stairwells tend to enhance stack-effect pressures and vertical airflow connectivity in commercial buildings. In tall buildings, the indoor-outdoor pressure difference can vary significantly with height.

Shaw and Tamura (1977) developed a method for estimating infiltration rates of tall buildings caused by wind and stack effects separately, based on the physics of fluid flow. The effects of internal partitioning and airflow connectivity of a building are captured using simple adjustment factors. Data from wind tunnel experiments are used to combine the wind and stack effects to give the overall air infiltration rates. Their model is briefly summarized here and applied in the analysis that follows.

The Shaw-Tamura model estimates the stack-driven air infiltration rate, $Q_{s}\left(\mathrm{~m}^{3} \mathrm{~s}^{-1}\right)$, by assessing the amount of airflow across the building perimeter $S(\mathrm{~m})$ over the height of the building through which infiltration occurs. 


$$
Q_{s}=C \cdot S \cdot \gamma \cdot\left(\rho \cdot g \cdot\left(\frac{T_{i}-T_{o}}{T_{i}}\right)\right)^{n} \cdot \frac{(\beta \cdot H)^{n+1}}{n+1}
$$

Here, $C$ and $n$ are leakage characteristics of the building as defined in equation $(1), T_{i}(\mathrm{~K})$ and $T_{o}$ $(\mathrm{K})$ are the indoor and outdoor temperature, respectively, $\rho\left(\mathrm{kg} \mathrm{m}^{-3}\right)$ is the outdoor air density, and $\mathrm{g}=9.8 \mathrm{~m} \mathrm{~s}^{-2}$. The neutral pressure level, $\beta(-)$, is the fraction of the building height, $H(\mathrm{~m})$, at which the indoor-outdoor pressure difference is zero. When the indoor temperature is higher than that outdoors, outdoor air infiltrates into the building from ground level up to $\beta H$, and exfiltrates from the building above that point. When the stack effect is reversed (i.e. $T_{o}>T_{i}$ ), air infiltrates from the top of the building down to $\beta H$ and exfiltrates below that level. The thermal draft coefficient, $\gamma(-)$, quantifies the resistance to internal airflow, accounting for partitions and connectivity. In a building with airtight separations at each floor, each story acts independently such that the stack effect is discontinuous from floor to floor, and $\gamma$ approaches 0 . If the internal air space is well connected vertically, then $\gamma$ approaches 1.

Wind generates areas of positive and negative pressure on the building envelope relative to inside. Typically, the windward wall(s) are pressurized with respect to indoors, and the adjacent wall(s) may be depressurized. These pressure disturbances drive air infiltration across the building envelope at a rate $Q_{w}\left(\mathrm{~m}^{3} \mathrm{~s}^{-1}\right)$, which is estimated as follows:

$$
Q_{w}=C \cdot(L \cdot H) \cdot \alpha \cdot\left(C_{p}^{\prime} \cdot \frac{1}{2} \cdot \rho \cdot U^{2}\right)^{n}
$$

where $L(\mathrm{~m})$ is the length of the building on the windward side (a bounding rectangle is used to estimate $L$ for buildings with an other-than-rectangular plan), $U\left(\mathrm{~m} \mathrm{~s}^{-1}\right)$ is the impinging wind speed at the building rooftop height, and $C, n$, and $\rho$ are as previously defined. Instead of accounting for the different wind pressure at each building façade, the Shaw-Tamura model normalizes the overall wind-driven air infiltration rate to the wind-pressure coefficient of the long wall, $C_{p}^{\prime}(-)$, which has a surface area $L H\left(\mathrm{~m}^{2}\right)$. Furthermore, $C_{p}{ }^{\prime}(-)$ is defined for the case in which wind impinges directly on the long wall. The wind-angle correction factor, $\alpha$, accounts for 
the effect of the wind impinging on the building at a different angle. Both $C_{p}{ }^{\prime}$ and $\alpha$ depend on building geometry, shielding from surrounding structures, and terrain effects.

A few empirical formulations have been proposed (Shaw and Tamura, 1977; Shaw, 1979) to combine the stack and wind effects to estimate the total air-infiltration rate. The different formulations give air infiltration rate estimates that agree to within $\sim 20 \%$. The formulations also indicate that the total air infiltration rate $\left(Q_{\text {total }}\right)$ is largely driven by either the stack or wind effect, whichever is greater. We use the following formulation because of its simplicity:

$$
Q_{\text {total }}=Q_{\text {large }} \cdot\left(1+0.24 \cdot\left(\frac{Q_{\text {small }}}{Q_{\text {large }}}\right)^{3.3}\right)
$$

where $Q_{\text {small }}$ and $Q_{\text {large }}$ are, respectively, the smaller and larger of $Q_{s}$ and $Q_{w}$.

\subsection{Ventilation Rates}

Most commercial buildings are equipped with a mechanical ventilation system that operates to deliver outside air to the building occupants. Without timely warning of and reaction to an outdoor contaminant release, many buildings will have mechanical ventilation operating when the contaminant plume reaches the building. Lagus and Grot (1995) and Cummings et al. (1996) measured the air-exchange rates in many small to mid-size commercial buildings with and without the ventilation system running. The distribution of air-exchange rates measured by the two studies with the ventilation system operating is roughly lognormal with $\mathrm{GM}=1.0 \mathrm{~h}^{-1}$ and $\mathrm{GSD}=2.2$. Infiltration alone produced air-exchange rates that were $10-80 \%$ of those with the ventilation system on, with a mean ratio of about $40 \%$.

Many buildings vary their ventilation rates according to occupancy level and season: when the outdoor temperature is mild, an "economizer mode" brings in large quantities of outdoor air to keep the building at a comfortable temperature in an energy efficient manner. When the outdoor temperature is too warm or too cold to be used this way, the rate of outdoor air supply is reduced to save energy. Grot and Persily (1986) found that the measured monthly 
average air-exchange rates of eight office buildings ranged from 0.3 to $1 \mathrm{~h}^{-1}$ during the winter months and were typically well over $1 \mathrm{~h}^{-1}$ in most buildings in spring and fall. The USEPA's Building Assessment Survey and Evaluation (BASE) measured the air-exchange rates of 100 randomly selected office buildings and collected data on the number of occupants and outdoor temperature (Persily et al., 2006). The distribution of air-exchange rates was found to be roughly lognormal with a central tendency $\left(\mathrm{GM}=1.1 \mathrm{~h}^{-1}\right)$ similar to those reported by Lagus and Grot (1995) and Cummings et al. (1996). However, the BASE study found a higher variability among measurements $(\mathrm{GSD}=3.4)$.

\section{Methods}

\subsection{Case Study}

A hypothetical release of duration $0.5 \mathrm{~h}$ is modeled for a downtown business district in a real city that we call "City B." The release source is $2 \mathrm{~m}$ above the ground. The outdoor concentrations are simulated using an atmospheric dispersion model known as the Lagrangian Operation Dispersion Integrator (Ermak and Nasstrom, 2000), implemented by the National Atmospheric Release Advisory Center at Lawrence Livermore National Laboratory using actual weather data. The model domain is $2 \times 2 \mathrm{~km}$, with a uniform grid resolution of $50 \times 50 \mathrm{~m}$. Outdoor concentration predictions were provided as 1-minute averages at each location. Fig. 2 depicts the predicted outdoor concentrations at the 5-m plane. For this model run, pollutant dispersion around buildings was not explicitly simulated. During the $2-\mathrm{h}$ simulation period, the outdoor temperature increases from 26 to $29{ }^{\circ} \mathrm{C}$. Wind blows from the southwest fairly uniformly across the entire area. The wind speed at $10 \mathrm{~m}$ above ground was roughly $2-3 \mathrm{~m} \mathrm{~s}^{-1}$. The plume takes about 10 minutes to travel $1 \mathrm{~km}$, a distance that carries it out of the model domain.

\subsection{Commercial Building Characteristics}

Three-dimensional building databases have been used to parameterize the urban morphology of cities (Ratti et al., 2002). In the present study, we used the US national building 
database managed by Los Alamos National Laboratory to obtain characteristics of buildings in City B, including height, footprint area, land use classification, and geographical location. Most of the buildings in the model domain are located in parts of the city that are classified as "commercial" and "service." Roughly half of the 600 buildings in the modeling domain encountered the toxic plume. Most of these buildings are less than $10 \mathrm{~m}$ tall and only 17 buildings are taller than $30 \mathrm{~m}$. The floor area of each building was estimated by multiplying the footprint area by the number of floors, which was estimated as the building height divided by 3 $\mathrm{m}$ per story and then rounded to the nearest integer. Buildings that encountered the toxic plume vary in size: their estimated floor areas range from 200 to $200,000 \mathrm{~m}^{2}$.

The air infiltration rates of buildings are predicted using the same meteorology parameters ( $\Delta T$ and $U$ ) used to predict plume dispersion. Most buildings in the downtown area of City B are offices. As illustrated in Fig. 1, buildings with a smaller footprint area and shorter height tend to have a higher air leakage. We applied the analysis of Price et al. (2006) to obtain estimates of $Q_{50} / A$ for office buildings of various sizes. Then, using equation (1), we solved for the distribution of $C$ and $n$. To do so, we first needed to define the relationship between $C$ and $n$. We found the following negative correlation between $C$ and $n$ from an analysis of the empirical air leakage data described in Price et al. (2006):

$$
n=0.232-0.0482 \times \ln (C)+\varepsilon
$$

where the regression residual $\varepsilon$ is approximately normally distributed with a mean of 0 and a standard deviation of 0.09 . The inverse correlation is expected, since large airflows (leaky buildings with large $C$ value) are resisted more by inertia $\left(Q \propto \Delta P^{0.5}\right)$, and small airflows (tight buildings with small $C$ value) are resisted more by viscosity $(Q \propto \Delta P)$. $C$ is solved by substituting equation (5) into equation (1) and by using the values of $Q_{50} / A$ from Price et al. (2006) for the various size classes of buildings. Then, we estimate $n$ deterministically as a function of $C$ at the different percentiles using equation (5). For example, for small buildings, the $5^{\text {th }}$ and $95^{\text {th }}$ percentile $C$ values are $5.0 \times 10^{-5}$ and $1.5 \times 10^{-3} \mathrm{~m} \mathrm{~s}^{-1} \mathrm{~Pa}^{-n}$, respectively, and the 
corresponding $n$ values are 0.71 and 0.55 . Table 1 shows $C$ and $n$ for building of other sizes to be used in Shaw-Tamura model.

The Shaw-Tamura model has a few adjustable parameters that require site-specific building data. We reviewed studies that reported measured values in buildings of $\gamma$ and $\beta$ (Tamura and Wilson, 1966, 1976; Shaw, 1980; Hayakawa and Togari, 1990), and $C_{p}^{\prime}$ (Grosso, 1992; Orme et al., 1994; Persily and Ivy, 2001). The available data are too limited to quantify the distributions of these parameters in a building stock. For simplicity, we have assumed that the same parameter values apply across all buildings in the model domain. The values chosen $(\gamma=$ $0.8, \beta=0.5$, and $C_{p}{ }^{\prime}=0.7$ ) roughly represent the estimated central tendency of the measurements reviewed. Favoring a simple model in the absence of strong empirical data, we further ignore the dependency of air infiltration rate on wind direction by setting $\alpha=1$ in all cases.

For buildings that are much smaller than those for which the Shaw-Tamura model is designed, we used the LBL infiltration model (Sherman and Grimsrud, 1980), which was developed for houses and is used for small commercial buildings because internal partitions are less important in smaller buildings. Buildings that we modeled with the LBL infiltration model have floor areas $<1000 \mathrm{~m}^{2}$ and are 3-story or less, about the same size as houses. About half of the buildings in the modeling domain of City B are treated using the LBL infiltration model. We modeled the stack-driven air infiltration assuming that half of the total leakage area is attributable to the vertical walls of the building and that there is no difference between the air leakage associated with the ceiling and the floor. For additional details see Chan et al. (2007b).

\subsection{Shelter-in-Place Effectiveness Metrics}

Time-varying indoor concentrations in buildings are modeled based on a material balance applied to a well-mixed interior space. If the perimeter of a building intersects with more than one grid cell in the outdoor concentration model, we calculate the average outdoor concentration experienced by the building as the average over all of the intersected grid cells, weighted by the fraction of building footprint that intersects each cell. All buildings are assumed to encounter the 
outdoor concentrations predicted at the 5-m plane. This assumption would tend to overpredict the vertically averaged outdoor concentration for the (few) very tall buildings in City B because the release source is near ground level.

Health effects for acute, high level exposure to many chemicals are not direct functions of the time-integrated concentrations to which a person is exposed; instead, the time histories of exposures are important. Typically, inhalation of a very high concentration for a short time is much worse than inhalation of a lower concentration for a long time, even if the time-integrated concentration is the same in both cases. The concept of "toxic load" has been developed to predict health effects from time-varying concentrations (Ten Berge, 1986). Toxic load is the time-integral of the chemical concentration raised to an empirical "toxic load exponent," $m$. The value of $m$ depends on the chemical and is typically in the range of 1 to 3 . The case $m=1$ implies that health effects depend only on the time-integrated exposure concentration. The toxic load that a person experiences at a time $t$ after the start of an exposure event is:

$$
\operatorname{TL}(t)=\int_{0}^{t}\left(C\left(t^{\prime}\right)\right)^{m} d t^{\prime}
$$

When the toxic load exceeds a certain value, known as the toxic load limit (TLL), adverse health effects may result. The US National Research Council has used this toxic load framework to derive acute exposure guideline levels (AEGLs) for many industrial toxic chemicals and warfare agents (NRC, 2003). Many of the toxic chemicals reviewed are expected to cause severe health effects for exposures on the order of $0.1-10 \mathrm{mg} \mathrm{m}^{-3}$ for a 1-h period. In our analysis, we consider two hypothetical chemicals: (1) a chemical with toxic load exponent $m=1$ and a toxic load limit (TLL) of $1 \mathrm{mg} \mathrm{m}^{-3} \mathrm{~h}$, and (2) a chemical with $m=2$ and a TLL of $2.7\left(\mathrm{mg} \mathrm{m}^{-3}\right)^{2} \mathrm{~h}$. With these choices of TLL, the number of people predicted to experience adverse health effects, if exposed to the outdoor plume, is roughly the same for the two chemicals. This treatment facilitates exploration of how SIP effectiveness of the building stock varies with toxic-load exponent. 
We quantified SIP effectiveness for each building in terms of two metrics: the casualty reduction factor (CRF) and the safety-factor multiplier (SFM), which are defined as follows (Chan et al., 2007a):

$$
\begin{aligned}
& \mathrm{CRF}=1-\frac{\text { Population }\left(\mathrm{TL}_{\text {in }}>\mathrm{TLL}\right)}{\text { Population }\left(\mathrm{TL}_{\text {out }}>\mathrm{TLL}\right)} \\
& \mathrm{SFM}=\frac{\mathrm{SF}_{\text {in }}}{\mathrm{SF}_{\text {out }}}=\frac{\left(\frac{\mathrm{TLL}}{\mathrm{TL}_{\text {in }}}\right)^{\frac{1}{m}}}{\left(\frac{\mathrm{TLL}}{\mathrm{TL}_{\text {out }}}\right)^{\frac{1}{m}}}=\left(\frac{\mathrm{TL}_{\text {out }}}{\mathrm{TL}_{\text {in }}}\right)^{\frac{1}{m}}
\end{aligned}
$$

CRF represents the fractional reduction in the expected number of casualties for populations sheltering indoors as compared with being exposed outdoors; $\mathrm{CRF}=0$ means no reduction and $\mathrm{CRF}=1$ means $100 \%$ reduction. In this analysis, we assumed that all buildings would have the same occupant density per unit floor area.

The SFM is the multiplicative extent to which sheltering enhances the safety factor (SF) of an exposed individual. The safety factor for an individual is the maximum factor by which the outdoor concentration could be multiplied without the person being at risk of experiencing adverse health effects. For example, if exposure to an outdoor concentration 4 times higher than actually occurred would have brought the person to the toxic load limit, their safety factor is 4 . If, by sheltering, their safety factor increases to 8 (i.e. by a factor of 2 ), then the safety factor multiplier for this person is 2 .

\subsection{Shelter-in-Place Scenarios}

In this paper, we focus on the benefit of shutting down the mechanical ventilation system as a simple strategy to enhance the effectiveness of sheltering in commercial buildings. We model two different time delays, 10 and 30 minutes, for shutdown of the systems after the start of the release. 
Rather than choosing a single air-exchange rate for each building, we consider each building's probabilistic air-exchange rate distribution as measured by Lagus and Grot (1995) and Cummings et al. (1996) with mechanical ventilation systems on. The air-exchange rates with mechanical ventilation are increased by $2-10 \times$ relative to the modeled air infiltration rates (Fig. 3). We assumed that there is no loss of the toxic chemical on filters or in the ductwork of the ventilation systems. For a conventional mechanical ventilation system exposed to a gaseous contaminant, this modeling assumption is reasonable. Note though that properly designed, installed and maintained air-filtration and air-cleaning systems could be effective at removing certain types of contaminants from a building's air supply and thereby provide improved SIP effectiveness (NIOSH, 2003).

We quantified the reduction of SIP effectiveness owing to the additional air exchange for several releases with different characteristics: $(1)$ linear $(m=1)$ versus nonlinear $(m=2)$ doseresponse, and (2) an inert versus a moderately sorptive chemical. In our earlier work (Chan et al., 2007a and 2007b), we found that there is a diminishing difference in SIP effectiveness among different $m$ values as $m$ increases. That is, while there is a striking difference in SIP effectiveness between $m=1$ and $m=2$, results are similar for $m=2$ and $m=3$. We also found that sorption of chemicals to indoor surfaces at a moderate rate is sufficient to offset the need for timely SIP in residential buildings (Chan et al., 2007b). The simulations in the present paper explore whether the same is true in commercial buildings. Commercial buildings have different amounts and types of indoor surfaces from those found in residential buildings, which could lead to different sorption characteristics. However, lacking data on which to base a refined sorption model, we use the parameters from the $\mathrm{NH}_{3}$ experiments by Karlsson and Huber (1996) to model moderate contaminant sorption in commercial buildings. 


\section{Results and Discussion}

\subsection{Effects of Air Leakage Variability}

Figure 4 shows the predicted outdoor and indoor concentrations at two buildings that are located at a street corner opposite each other, exposed to similar but not identical chemical concentrations as a function of time. Building 1 has 16-stories and $\sim 120,000 \mathrm{~m}^{2}$ of floor area. Building 2 is much smaller: 3 -story and $\sim 1600 \mathrm{~m}^{2}$. The central tendency of the air infiltration rate distribution (in air-changes per hour) for the smaller building is $4 \times$ higher than that of the larger building. Two main factors contribute to this difference. First, per unit envelope surface area, small buildings are leakier than large buildings (see $\S 2.1$ and $\S 3.2$ ). In this case, we predicted that, on average, the envelope of Building 2 is $60 \%$ leakier than that of Building 1 . Second, small buildings have a higher ratio of exterior surface area to volume than do large buildings. Air infiltration scales with the surface area of the building envelope (equations (2) and (3)), so the airflow rate per unit building volume is expected to be lower in large buildings as compared with small ones. Consequently, the maximum indoor concentration predicted in the (smaller) Building 2 is about $2 \times$ higher than that in the (larger) Building 1, even though Building 2 is exposed to a slightly lower outdoor concentration.

The cumulative toxic load if people were exposed to the outdoor concentrations at the two buildings would exceed the toxic load limit in the case of $m=1$. Consider the scenario where people took shelter before the start of the release and remained indoors for the entire 2-h event duration. If the actual air infiltration rate of Building 1 is less than the $95^{\text {th }}$-percentile predicted value, an adverse health effect is not expected for those who took shelter. People in Building 2 are at a risk of adverse health effects unless the actual air infiltration rate of the building is below the $70^{\text {th }}$-percentile predicted value. In other words, we predict a $30 \%$ chance that people in Building 2 would be at risk from adverse health effects while sheltering indoors, whereas this probability is only $5 \%$ in Building 1 .

We can summarize the difference in SIP effectiveness of these two buildings in terms of the safety-factor multiplier. A building provides more effective shelter if it reduces the indoor 
toxic load with respect to the outdoor value by a larger extent (equation (8)). The median SFM for Building 1 is 12, whereas Building 2 has a median SFM of only 3.6 (Fig. 5).

After determining the probabilistic distribution of SFM at each building, we then computed the expected distribution of SFM for the entire community. If all buildings are weighted equally, most SFM values are expected to fall between 2 to 20 . However, when evaluating the SIP effectiveness of a building stock for protecting populations, more weight should be given to large buildings because more occupants are expected to be there. In the present analysis, we use floor area as a proxy for the number of occupants and ignore other factors (e.g., time of day, building type) that can affect building occupancy. The populationweighted SFM distribution is higher in this case than if all buildings were weighted equally, because the predicted air infiltration rates are lower in large buildings.

Among the 84 buildings that are exposed to outdoor concentrations high enough to exceed the toxic load limit when $m=1$, more than $1 / 3$ maintained indoor concentrations at less than the toxic load limit. Most of these buildings are located at the fringe of the plume. The remaining $2 / 3$ of the buildings may or may not ensure a safe indoor environment during SIP, depending on their indoor-outdoor air-exchange rates. We computed the expected number of building occupants who might suffer from adverse health effects (i.e., for whom the toxic load limit is exceeded) according to the probabilistic air infiltration distribution. For example, consider a building in which the indoor toxic load would not exceed the TLL unless the actual air infiltration rate of the building is higher than the $95 \%$-precentile predicted value. In this building, the likelihood of the population exceeding the toxic load limit while sheltering is $5 \%$.

For this case study, we found that the likelihood of indoor toxic loads exceeding the toxic load limit is in the range $0-30 \%$ in 31 buildings, $30-70 \%$ in 13 buildings, and $>70 \%$ in 9 buildings. Comparing these estimates with the outdoor values using equation 7 , we predict that the community casualty reduction factor is $\mathrm{CRF}=0.78$ for this case: the number of casualties indoors is predicted to be about $80 \%$ lower than if everyone were exposed to the outdoor plume. Because buildings reduce peak concentrations from short-term releases, SIP effectiveness 
improves as the dose-response relationship becomes more nonlinear. At $m=2$, the CRF increases to 0.91 . Only 18 buildings are at risk of having indoor toxic loads exceeding the toxic load limit. Among these buildings, the likelihood of indoor toxic loads exceeding the toxic load limit is in the range $0-30 \%$ in 9 buildings, $30-70 \%$ in 6 buildings, and $>70 \%$ in 3 buildings.

\subsection{Ventilation}

Many more buildings would be at risk of having indoor concentrations exceeding the toxic load limit if their mechanical ventilation systems remained on during the release event. With the mechanical ventilation system on, all buildings are modeled to have the same probabilistic air-exchange rate as shown in Fig. 3. Even so, there are slight differences in SIP effectiveness among buildings in terms of the SFM, because each building encounters a different outdoor concentration time profile, depending on its location relative to the release site. In general, for a nonreactive pollutant, the longer a building is exposed to a chemical plume, the closer the indoor concentration approaches the outdoor value, and the lower is the SIP effectiveness. In this case study, in the condition that mechanical ventilation is maintained throughout the event, all buildings have an SFM less than 2, except the 10\% of buildings that have very a low ventilation rate, in the vicinity of $0.3 \mathrm{~h}^{-1}$. The predicted median populationweighted SFM is 1.2, which is a factor of 8 smaller than if buildings turned off their mechanical ventilation systems promptly during the release. If ventilation systems are left on, then SIP is predicted to be only modestly effective in reducing casualties. The benefit is only $6 \%$ (equation 7 indicates $\mathrm{CRF}=0.064)$ as opposed to the predicted $78 \%$ reduction if the mechanical ventilation systems are off. This example illustrates the critical importance of prompt and effective HVAC control if commercial buildings are to be used for shelter-in-place.

\subsection{Effects of Sorption and Response Time Delay}

For a given release scenario, three factors can enhance SIP effectiveness. One is a high toxic load exponent, $m$, of the chemical in the plume. For a chemical with high $m$, reducing the peak indoor concentration relative to that outdoors is an effective way to reduce the risk of 
adverse health effects. A second factor is the loss of contaminant to indoor surfaces either by reversible sorption, which lowers peak indoor concentrations, or by irreversible decomposition, which reduces both peak and time-averaged concentrations. A third factor is the timing of the SIP response: prompt initiation of SIP by changing building operation and configuration to minimize air exchange and prompt termination of SIP by exiting from the building when it is safe to do so. We evaluated the influence of these three factors on SIP effectiveness in terms of SFM and CRF and present illustrative results in Fig. 6. As expected, SIP is more effective when $m=2$ instead of 1 and when the contaminant sorbs to indoor surfaces. Furthermore, when both of these factors are favorable for effective SIP, prompt termination is not critical to ensure effectiveness. We computed the SFM and CRF in the case that sheltering is terminated either $1 \mathrm{~h}$ or $2 \mathrm{~h}$ after the onset of the release. With sorption and $m=2$ (see bottom right frame of Fig. 6), the values of SFM and CRF change only modestly as a function of termination time. In other scenarios, getting people out of contaminated buildings as soon as it is safe to do so can save lives. In practice, there obviously would be other factors to consider in deciding when to end SIP. Nonetheless, it is important for emergency responders to assess the trade-offs of taking shelter for too long in buildings that have been exposed to a contaminant posing an acute hazard.

Large commercial buildings tend to have lower air infiltration rates than do single-family residences. This difference translates to lower indoor concentrations during the first few hours of a release event and thus a higher degree of protection for SIP in large commercial buildings. An SFM in the range of 50 or higher and CRF values near 0.9, as illustrated in Fig. 6, would be difficult to achieve in a residential neighborhood. On the other hand, the decline in SIP effectiveness is more precipitous in commercial buildings if SIP is initiated long after the release has started. Only a moderate fraction of houses or apartments will typically have many open windows and doors at any given time, resulting in air change rates of 0.3 to $1 \mathrm{~h}^{-1}$. However, a large majority of commercial buildings are likely to be mechanically ventilated while occupied and are expected to have elevated air-exchange rates, on the order of $0.4-2.5 \mathrm{~h}^{-1}$. It is important to promptly shut off the mechanical ventilation system fans in commercial buildings when taking 
shelter under all release scenarios. Fig. 6 shows that the timing for turning off ventilation systems is a decisive factor controlling SIP effectiveness. Sorption alone is not sufficient to offset the large loss in SIP effectiveness if mechanical systems continue to operate after the plume arrives, because the high air-exchange rate brings in new contaminant molecules from outdoors, rapidly replacing contaminants removed by sorption. A chemical with a higher toxic load exponent, or one that sorbs faster on indoor surfaces than the case considered here, might allow for a longer lag time before it is essential to shut off ventilation; however, an expedited response to shut off mechanical ventilation systems would remain advisable even in such cases.

If SIP cannot be initiated until after the release has already stopped, then little can be gained by shutting off ventilation systems. This point is illustrated in Fig. 6, where the estimated SFM and CRF values for the ventilation-on case are almost the same, if not slightly higher, than if buildings were to turn off their ventilation systems after the release has came to an end (i.e., following 30-min delay). In the event of a short release coupled with late notice of its occurrence, emergency responders must be aware of the risk of trapping contaminants indoors when instructing building managers to turn off their mechanical ventilation systems.

\subsection{Spatially Varying Indoor Concentrations}

The analyses presented so far have assumed that the air within a building is well mixed. In large buildings, this assumption might not hold owing to internal partitions or the use of multiple air-handling units in the mechanical ventilation system. In such cases, different indoor concentrations could be present in different building zones. In the simplest treatment beyond a single well-mixed zone, a building can be modeled as having two coupled and independently well-mixed zones. We consider one possible configuration of a two-zone system in which the building has an outer perimeter zone and an inner core zone. The two zones are interconnected, but only the outer zone exchanges air with the outdoors. The governing equations for the indoor concentrations of an inert species in these two zones owing to an outdoor release are as follows: 


$$
\begin{aligned}
& V_{p i} \frac{d C_{p i}}{d t}=Q_{e x t} C_{\text {out }}-Q_{e x t} C_{p i}-\left[Q_{i n t} C_{p i}-Q_{i n t} C_{c}\right] \\
& V_{c} \frac{d C_{c}}{d t}=Q_{\text {int }} C_{p i}-Q_{i n t} C_{c}
\end{aligned}
$$

where $C_{p i}$ and $C_{c}$ are the indoor concentrations in the perimeter and core zone, respectively. Two key parameters characterize this simple two-zone system. The first is the relative volume of the two zones, denoted by $V_{p i}$ and $V_{c}$ for the perimeter and core zone, respectively. The second is the airflow rate between the two zones, $Q_{\text {int }}$, relative to the airflow rate between the perimeter zone and the outdoors, $Q_{e x t}$. In the analysis presented here, we assumed that $Q_{e x t} /\left(V_{p i}+V_{c}\right)$ and $Q_{\text {int }} / V_{c}$ can independently take on one of two values: 0.25 and $1 \mathrm{~h}^{-1}$. The first term corresponds to the air-exchange rate $(\mathrm{ACH})$ for a well-mixed building. The second term quantifies the interconnectivity between the two zones and is denoted as $\mathrm{ACH}_{\text {int }}$ in Fig. 7.

Fig. 7 shows the simulated indoor concentrations for Building 1 examined earlier (see Fig. 4), modeled as a two-zone environment. In addition to the flow variations, we modeled two cases, with $V_{c}$ as $20 \%$ or $80 \%$ of the total building volume, respectively. The perimeter zone of the building is always subject to a higher indoor concentration than in the one-zone case, owing to a decrease in volume of indoor air within which the majority of the contaminant is diluted. However, if people were to shelter in the core zone of the building, their exposure to the toxic contaminants could be substantially reduced. The lowest indoor concentration was predicted to occur in the core zone when both $\mathrm{ACH}$ and $\mathrm{ACH}_{\text {int }}$ are low $\left(0.25 \mathrm{~h}^{-1}\right)$. The highest indoor concentration was predicted to occur in the perimeter zone, when contamination was trapped in the perimeter zone due to a low $\mathrm{ACH}_{\text {int }}\left(0.25 \mathrm{~h}^{-1}\right)$ after entering into the building at a high rate $\left(\mathrm{ACH}=1.0 \mathrm{~h}^{-1}\right)$. The highest perimeter concentrations are predicted when the core zone makes up the bulk of the building $\left(V_{c}=0.8 \mathrm{~V}\right)$ so that the volume of air for dilution in the perimeter zone is small. The highest and the lowest predicted indoor concentrations differ by a factor of 15 .

Aside from a generally lower indoor concentration in the core zone, the increase in corezone concentrations is more gradual relative to the one-zone well-mixed building. In general, a lower airflow between the two zones leads to a more gradual increase in indoor concentration in 
the core zone. This illustrative case shows that taking shelter in the inner core of a building could be an effective strategy to further enhance the effectiveness of SIP, especially if the intrazonal flow between the core and the perimeter can be minimized.

\section{Conclusion}

Shelter-in-place (SIP) effectiveness has been explored for the commercial building stock of a city challenged by a hypothetical short-term $(0.5 \mathrm{~h})$ outdoor release of a toxic gas. We modeled the air infiltration rate distributions of commercial buildings in a real city using the Shaw-Tamura and LBL infiltration models. The air-leakage characteristics of the buildings were estimated, based on measurements of 267 commercial buildings (Price et al., 2006). Model results were evaluated using two metrics to quantify SIP effectiveness: the safety-factor multiplier (SFM) and the casualty reduction factor (CRF). Since the goal of SIP is to protect people, health-relevant metrics of effectiveness are important for assessing SIP performance.

Commercial buildings can be effective shelters if their mechanical ventilation systems are turned off before ingesting substantial amounts of toxic material. Without mechanical ventilation, the air infiltration rate of large commercial buildings is low compared to houses, mostly because of the small surface-to-volume ratio of large buildings. The infiltration rate for small commercial buildings, and for houses, is high enough that these buildings may not provide effective shelter, especially in the case of a long-duration toxic plume. A key parameter is the duration of the plume compared to the air exchange rate of the building.

Potentially, taking shelter in the core of a building - i.e., in an area with no direct air exchange with the outdoors - can further reduce exposure of occupants to the toxic chemicals released outdoors.

Chemical sorption on indoor surfaces and nonlinear dose-response relationships tend to enhance the effectiveness of SIP; however, these factors may not be enough to offset the large amount of contaminants brought into a building if its mechanical ventilation system continues to operate throughout the event. 
The modeling framework presented in this series of papers can be used in both pre-event planning and to guide real-time emergency response. In the planning mode, the model can be exercised to identify scenarios where SIP is sufficient to eliminate most adverse health effects and also scenarios where quick relocation of occupants following a release would be necessary to ensure safety. Comparing different scenarios can illustrate the benefit of fast response and community cooperation, as well as the effectiveness of proactive measures. In response to an actual event, a real-time modeling capability (perhaps as an extension to existing real-time toxic event models) can provide an assessment of SIP effectiveness specific to the release event at hand. Models can identify areas where building occupants are most likely to need assistance, and can provide rapid prediction of the expected number of casualties and thus help guide the appropriate emergency response.

\section{Acknowledgement}

This work was supported by the Office of Chemical Biological Countermeasures, of the Science and Technology Directorate of the Department of Homeland Security, and performed under US Department of Energy Contract No. DE-AC02-05CH11231.

\section{References}

Chan WR, Nazaroff WW, Price PN, Gadgil AJ (2007a). Effectiveness of urban shelter-in-place.

I: Idealized conditions. Atmospheric Environment 41, 4962-4976.

Chan WR, Nazaroff WW, Price PN, Gadgil AJ (2007b). Effectiveness of urban shelter-in-place.

II: Residential districts. Atmospheric Environment 41, 7082-7095.

Cummings JB, Withers CR, Moyer N, Fairey P, McKendry B (1996). Final report: uncontrolled air flow in non-residential buildings. FSEC-CR-878-96. Cocoa, FL: Florida Solar Energy Center.

Ermak DL, Nasstrom JS (2000). A Lagrangian stochastic diffusion model for inhomogeneous turbulence. Atmospheric Environment 34, 1059-1068. 
Grosso M (1992). Wind pressure distribution around buildings: a parametrical model. Energy and Buildings 18, 101-131.

Grot RA, Persily AK (1986). Measured air infiltration and ventilation rates in eight large office buildings. In Trechsel HR, Lagus PL (Eds.), Measured Air Leakage of Buildings (pp. 151183). ASTM STP 904. Philadelphia: American Society for Testing and Materials.

Hayakawa S, Togari S (1990). Simple test method for evaluating exterior wall airtightness of tall office buildings. In Sherman MH (Ed.), Air Change and Airtightness in Buildings (pp. 231245). ASTM STP 1067. Philadelphia: American Society for Testing and Materials.

Karlsson E, Huber U (1996). Influence of desorption on the indoor concentration of toxic gases. Journal of Hazardous Materials 49, 15-27.

Lagus PL, Grot RA (1995). Consultant report: air change rates in non-residential buildings in California. Lagus Applied Technology, Inc., P400-91-034BCN. Sacramento, CA: California Energy Commission.

McWilliams JA (2002). Review of airflow measurement techniques. Annotated Bibliography 12, Air Infiltration and Ventilation Centre, Coventry, UK.

NICS (2003). Shelter in place at your office - a general guide for preparing a shelter in place plan in the workplace. National Institute for Chemical Studies, Charleston, WV.

NIOSH (2003). Guidance for filtration and air-cleaning systems to protect building environments. Washington, DC: National Institute for Occupational Safety and Health. NRC (2003). Acute Exposure Guideline Levels for Selected Airborne Chemicals: Volume 3. Subcommittee on Acute Exposure Guideline Levels, Committee on Toxicology, National Research Council. Washington DC: National Academies Press.

Orme M, Liddament M, Wilson A (1994). An analysis and data summary of the AIVC's numerical database. Technical Note 44. Coventry, UK: Air Infiltration and Ventilation Centre.

Persily AK (1999). Myths about building envelopes. ASHRAE Journal, March, 39-47. 
Persily AK, Ivy EM (2001). Input data for multizone airflow and IAQ analysis. NISTIR 6585. Gaithersburg, MD: National Institute of Standards and Technology.

Persily AK, Gorfain J, Brunner G (2006). Survey of ventilation rates in office buildings. Building Research and Information 34, 459-466.

Price PN, Chang SC, Sohn MD (2004). Characterizing buildings for airflow models: what should we measure? LBNL-55321. Berkeley, CA: Lawrence Berkeley National Laboratory.

Price PN, Shehabi A, Chan WR (2006). Indoor outdoor air leakage of apartments and commercial buildings. PIER Energy Related Environmental Research Program. CEC 5002006 111. Sacramento, CA: California Energy Commission.

Proskiw G, Phillips B (2001). Air leakage characteristics, test methods, and specifications for large buildings. Ottawa, Canada: Canada Mortgage and Housing Corporation.

Ratti C, Di Sabatino S, Britter R, Brown M, Caton F, Burian S (2002). Analysis of 3-D urban databases with respect to pollution dispersion for a number of European and American cities. Water, Air, and Soil Pollution: Focus 2, 459-469.

Sabiha AG, Devaull J, Salmi D, Biagi A, Grek K, Nelson T (2001). Model emergency plan for schools. Martinez, CA: Contra Costa County Community Awareness \& Emergency Response (CAER) Group.

Shaw CY, Tamura GT (1977). The calculation of air infiltration rates caused by wind and stack action for tall buildings. ASHRAE Transactions 83(2), 145-158.

Shaw CY (1979). A method for predicting air infiltration rates for a tall building surrounded by lower structures of uniform height. ASHRAE Transactions 85(1), 72-84.

Shaw CY (1980). Wind and temperature induced pressure differentials and an equivalent pressure difference model for predicting air infiltration in schools. ASHRAE Transactions $86(1), 268-279$.

Sherman MH, Grimsrud DT (1980). Measurement of infiltration using fan pressurization and weather data. LBNL-10852. Berkeley, CA: Lawrence Berkeley National Laboratory. 
Sherman MH, Chan WR (2006). Building air tightness: research and practice. In Santamouris M, Wouters P (Eds.), Building Ventilation: The State of the Art (pp. 137-162). London, UK: Earthscan.

Tamura GT, Wilson AG (1966). Pressure differences for a nine-story building as a result of chimney effect and ventilation system operation. ASHRAE Transactions 72(1), 180-189.

Tamura GT, Wilson AG (1976). Pressure differences caused by chimney effect in three high buildings. ASHRAE Transactions 73(2), 1.1-1.10.

Ten Berge WF, Zwart A, Appelman LM (1986). Concentration-time mortality response relationship of irritant and systemically acting vapours and gases. Journal of Hazardous Materials 13, 301-309. 


\section{Figure Captions}

Fig. 1. Air leakage measurements of 267 buildings measured at $50 \mathrm{~Pa}$ (data from Price et al., 2006). Analysis in the cited work also provided estimates of air leakage as a function of building type, of which two examples are shown here.

Fig. 2. Outdoor concentrations predicted at 5, 15, 25, and 35 minutes from the onset of a $0.5-\mathrm{h}$ release. The concentrations are 1-minute averages at $2 \mathrm{~m}$ above ground, normalized to the highest predicted value. Outlined are the building footprint areas.

Fig. 3. Distribution of air-exchange rate caused by infiltration only and with mechanical ventilation systems on. The air infiltration of buildings in City B is modeled using the ShawTamura and LBL infiltration models. The air-exchange rates of buildings were measured by (1) Lagus and Grot (1995) and Cummings et al. (1996), and (2) Persily et al. (2006), under normal operating conditions.

Fig. 4. Predicted outdoor (left y-axis, shaded) and indoor concentrations (right y-axis) of two buildings. The indoor concentrations are predicted using the $5^{\text {th }}, 50^{\text {th }}$ (median), and $95^{\text {th }}$ percentile of each building's air infiltration rate distribution.

Fig. 5. Predicted Safety Factor Multiplier (SFM) for the hypothetical 0.5-h release in City B. A total of 606 buildings are exposed. In addition, the results for Buildings 1 and 2 are plotted to show the effect of different air infiltration distribution (see Fig. 4).

Fig. 6. SIP effectiveness measured in terms of safety-factor multiplier (SFM, left y-axis) and casualty reduction factor (CRF, right y-axis) under different release scenarios. The results of 16 simulations are summarized here: (i) $m=1,2$; (ii) with and without sorption; (iii) ventilation turned off immediately (no delay), with 10 or 30 minutes delay, and remains on throughout the 2-h simulation (ventilation). Further, SFM and CRF are evaluated at two moments in time: (A) 1 hour and (B) 2 hours after the onset of release.

Fig. 7. Predicted indoor concentrations of Building 1 using a two-zone system at two airexchange rates with the outdoors $(\mathrm{ACH})$, and two interzonal airflow rates $\left(\mathrm{ACH}_{\mathrm{int}}\right): 0.25$ and 1.0 $\mathrm{h}^{-1} . V_{c}$ is the core zone volume, expressed here as a fraction of the total building volume $(V)$. The remaining parts of the building are the perimeter zone. The perimeter zone concentrations are always above the prediction of the single well-mixed zone, as illustrated in the bottom left frame. 


\section{Figures}

Fig. 1

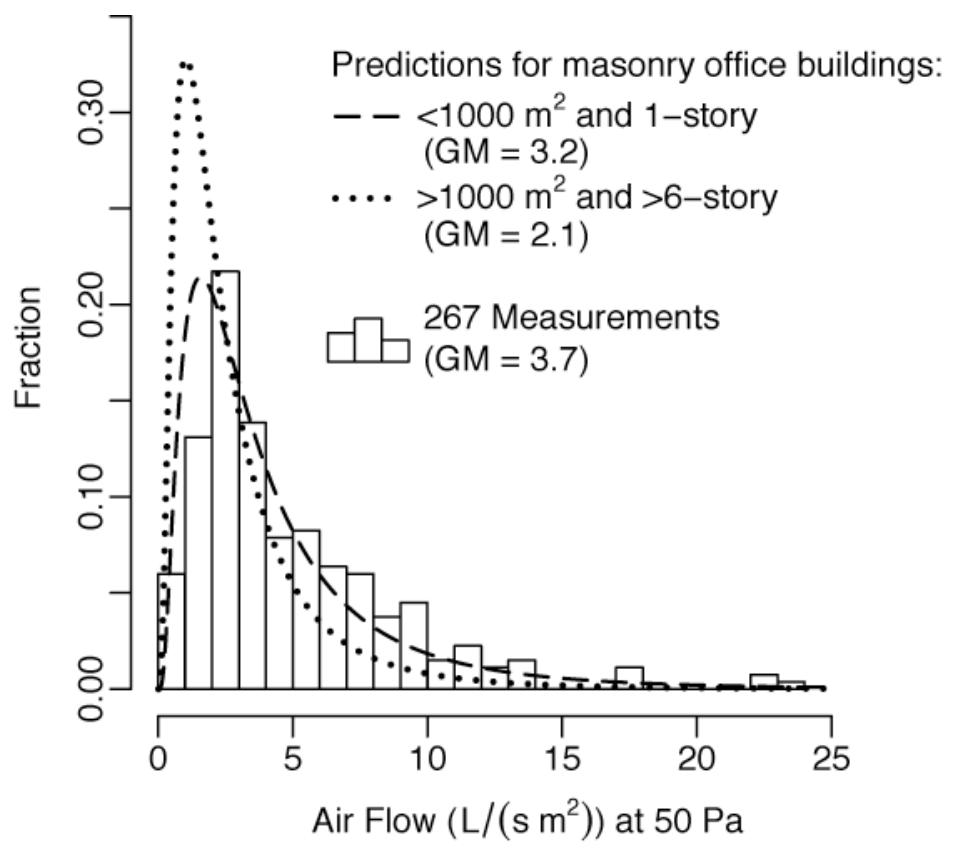


Fig. 2
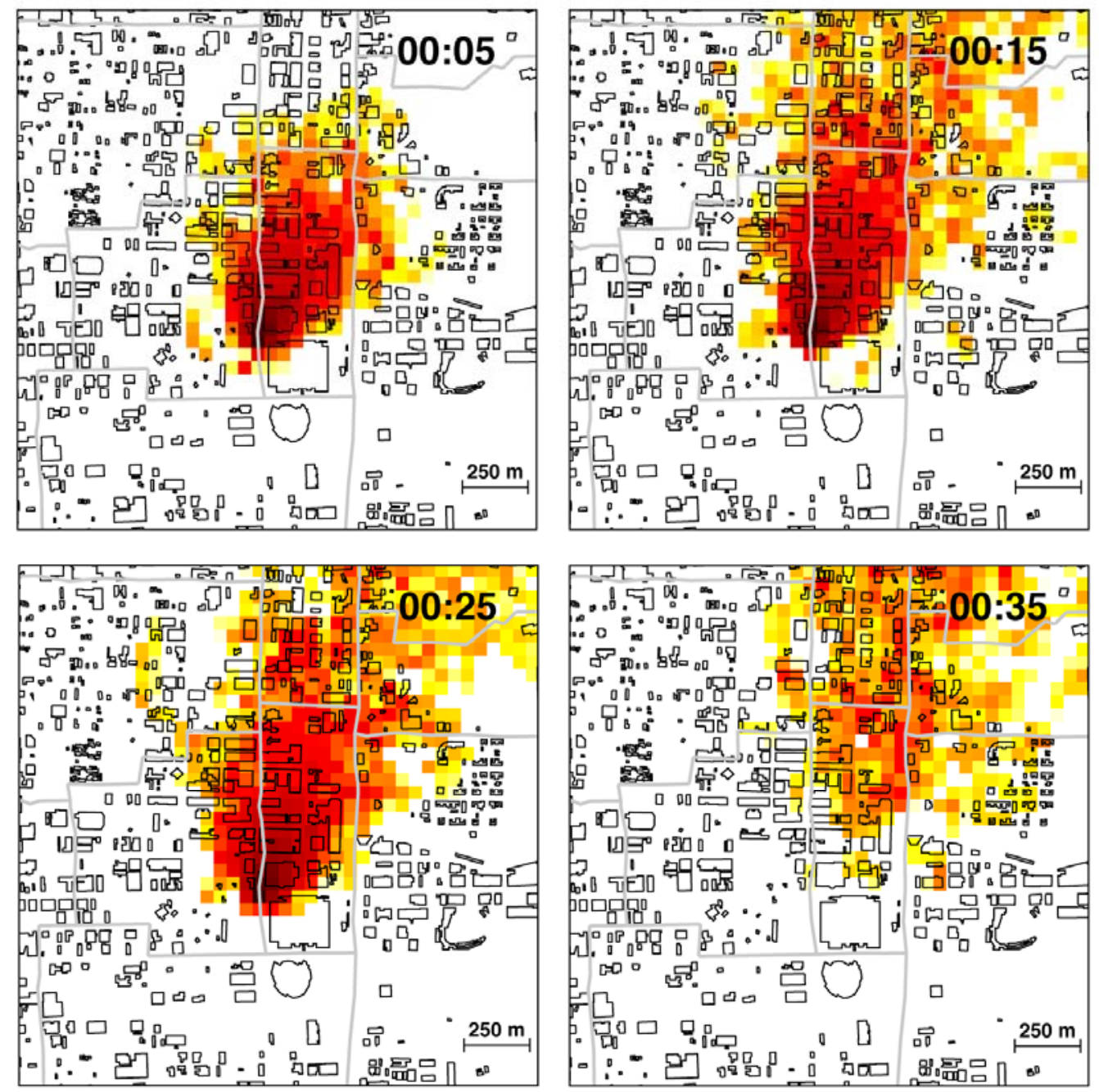

Normalized $10^{-0.5} \quad 10^{-1.0} \quad 10^{-1.5}$ $10^{-2.0} \quad 10^{-2.5} \quad 10^{-3.0} \quad 10^{-3.5} \quad 10^{-4.0}$ Concentration 
Fig. 3

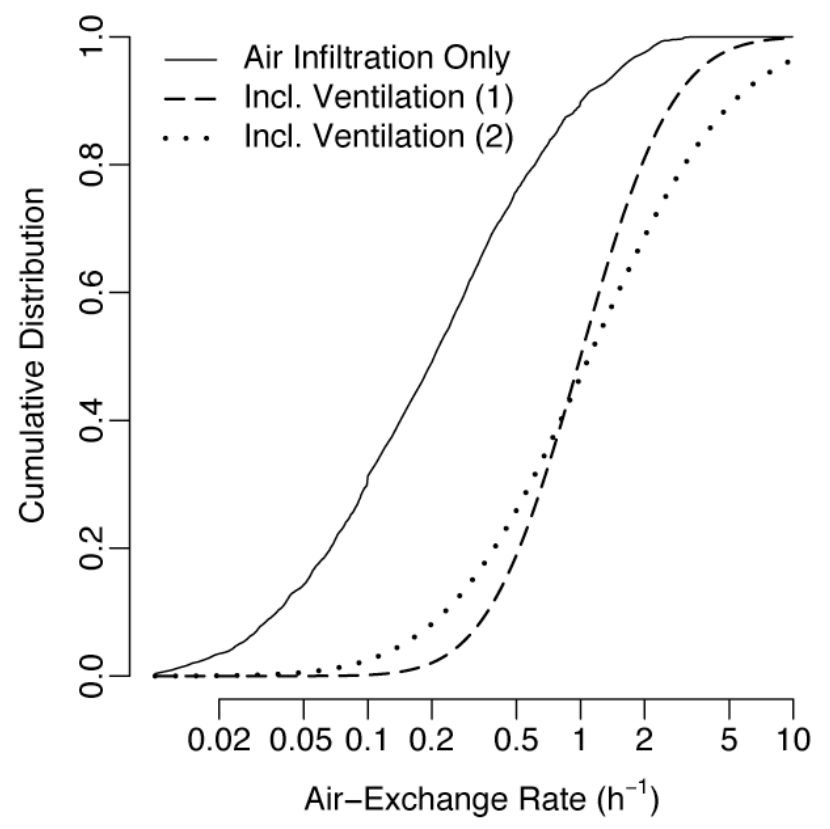

Fig. 4

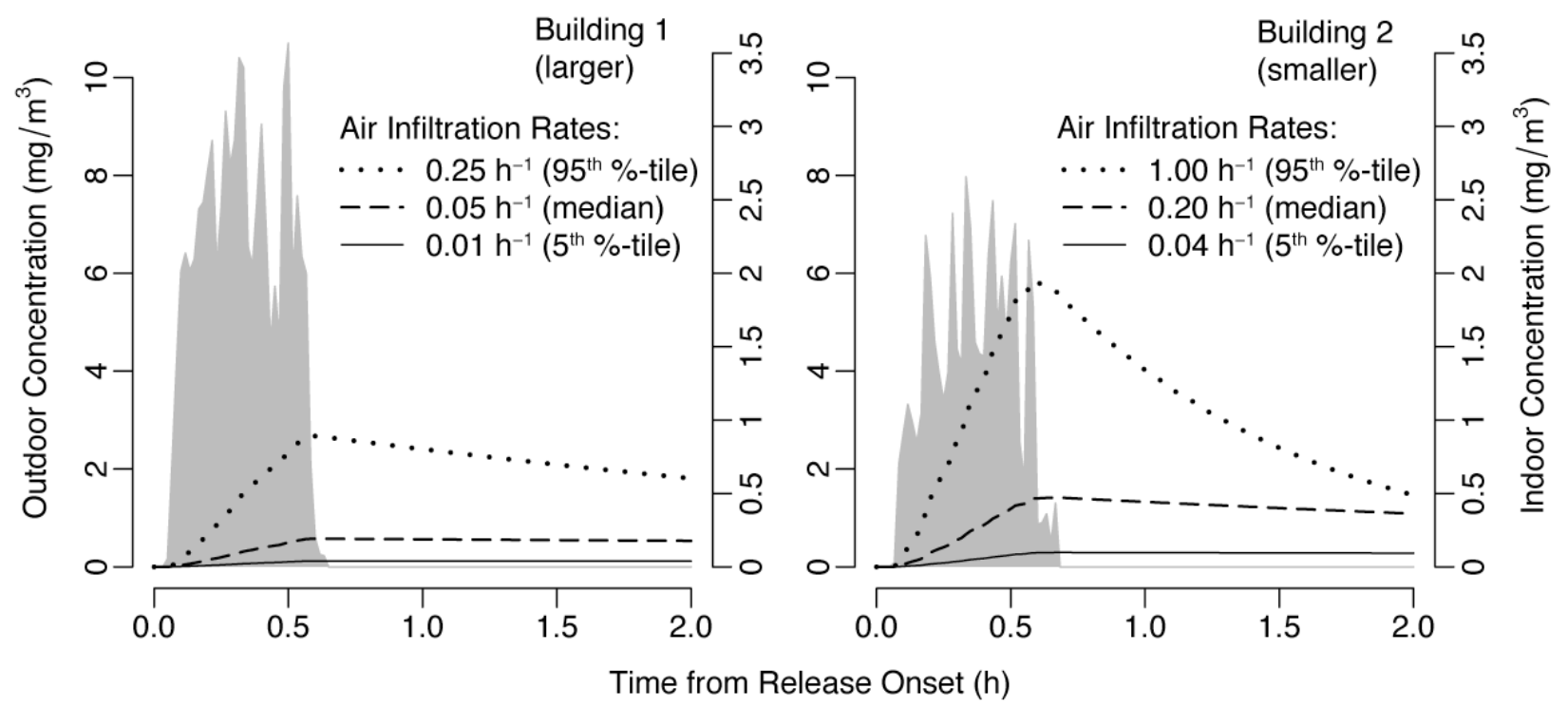


Fig. 5

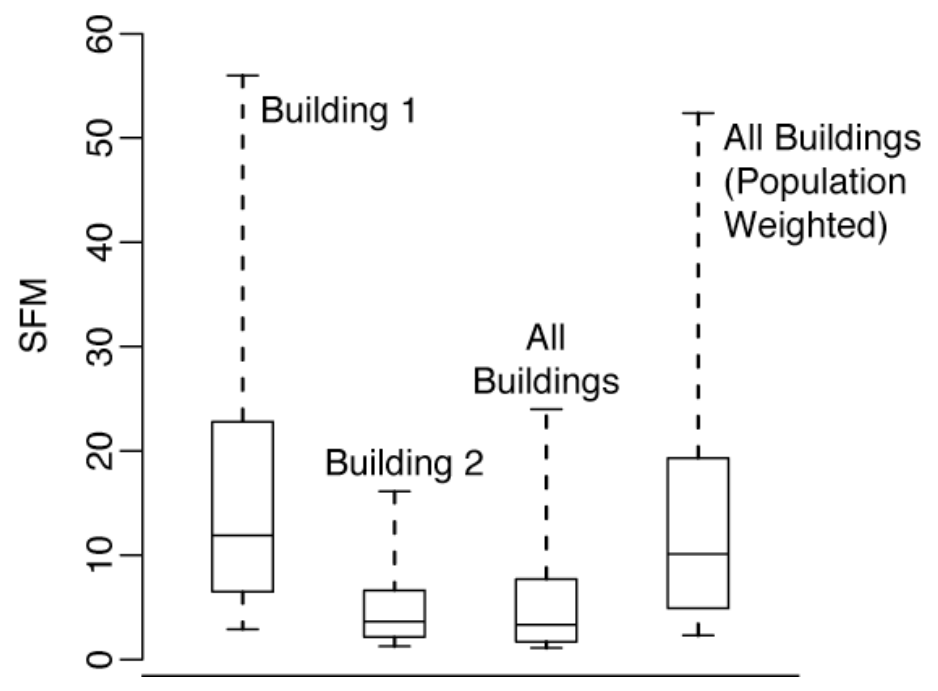


Fig. 6
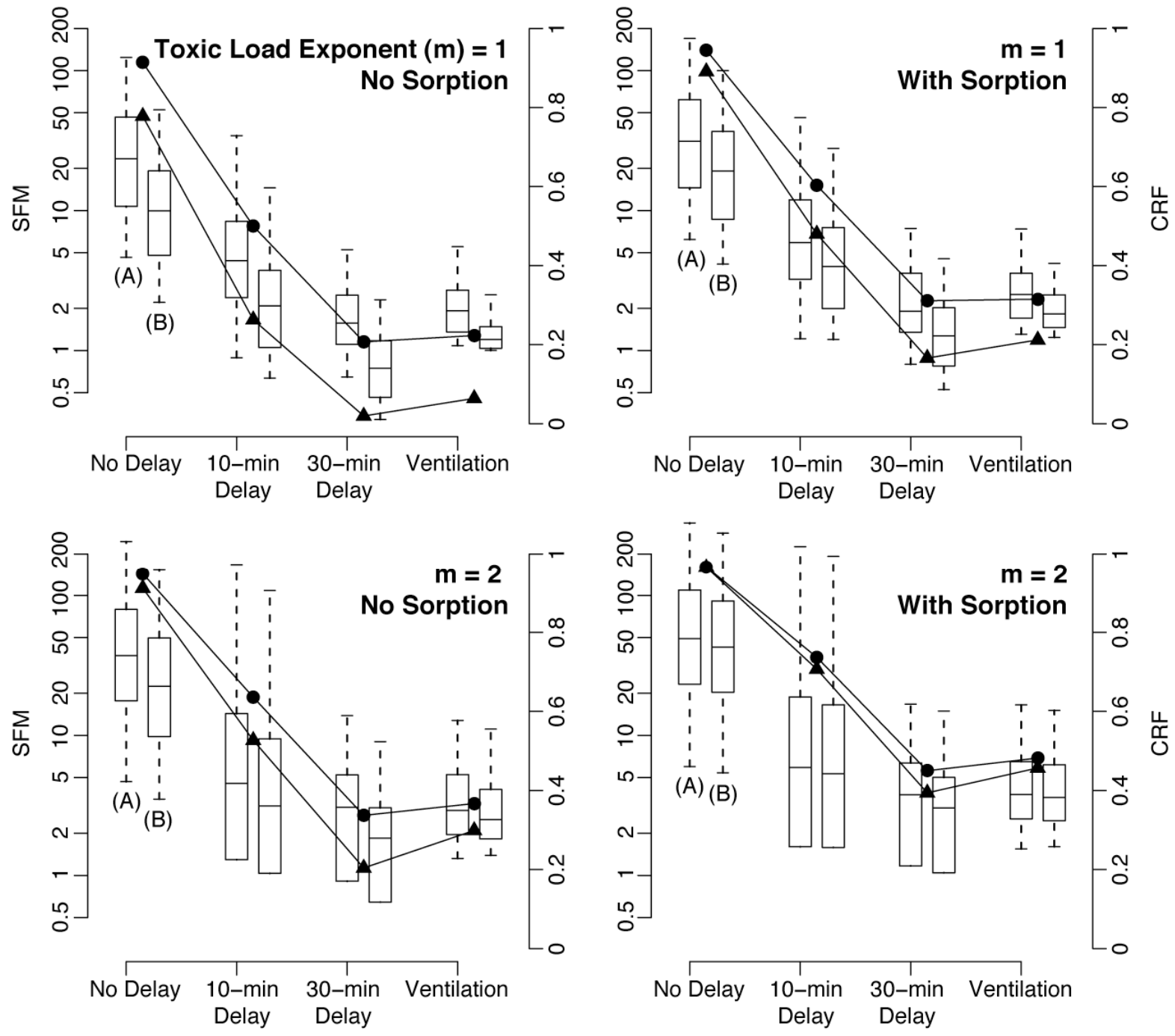

(A) SIP Terminated 1 hour after Onset of Release 
Fig. 7
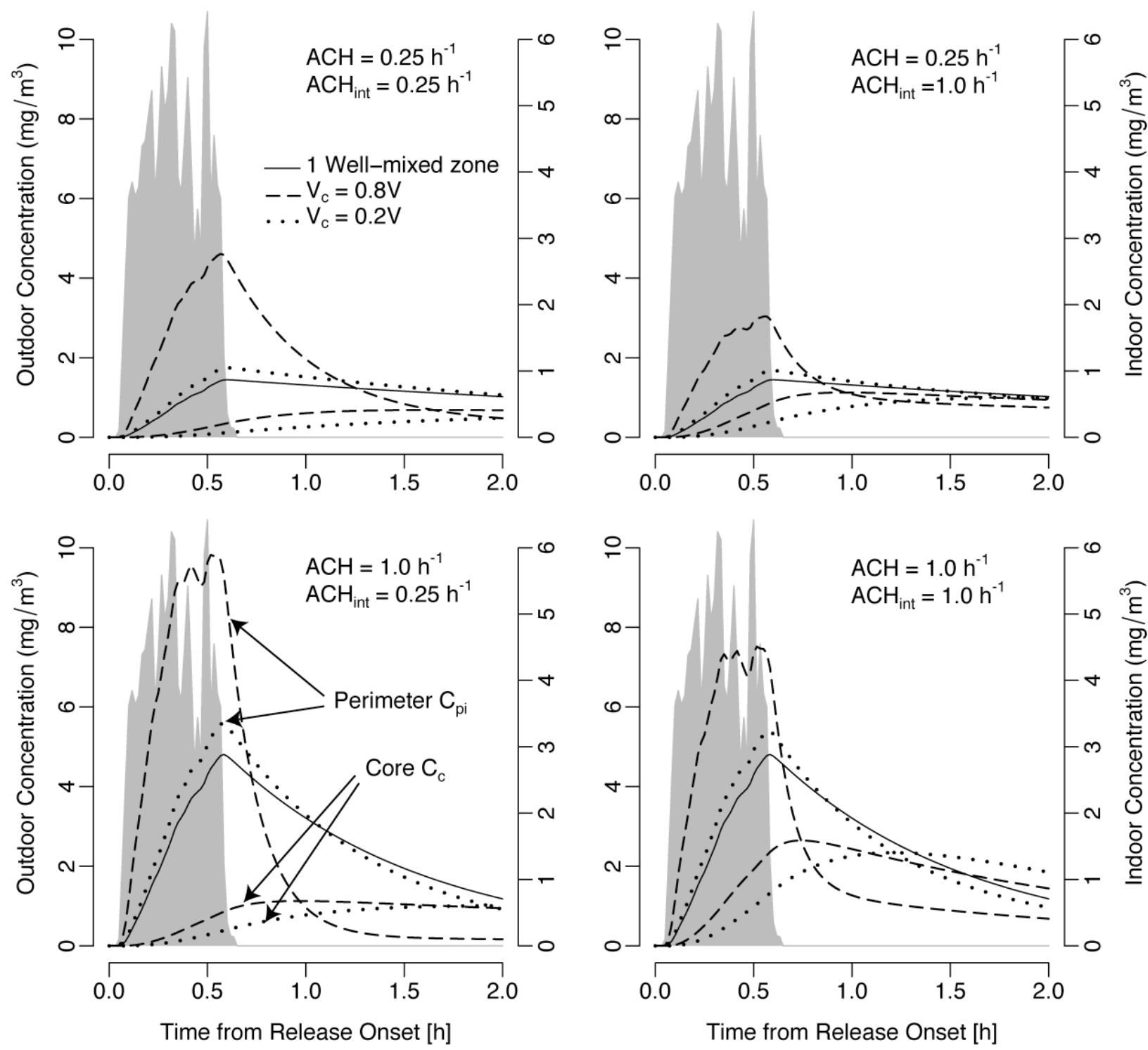


\section{Table}

Table 1. Air leakage characteristics of buildings modeled in City B.

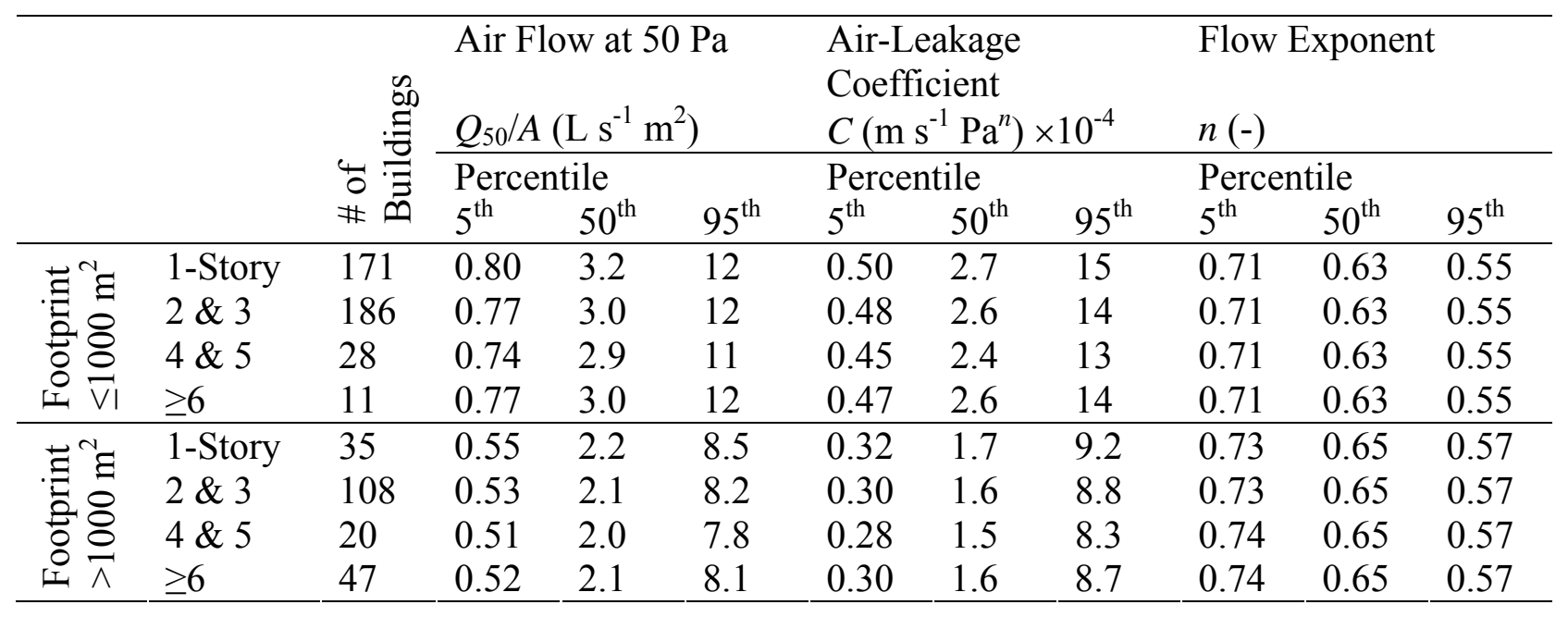

